\title{
El análisis del ambiente competitivo en la gestión de bibliotecas
}

Por Francisco J. Bonachera Cano

NUESTRA EXPERIENCIA DE MÁS DE DIEZ AÑOS trabajando en el sector público en diversas y muy diferentes unidades de información, junto con las lecturas frecuentes de trabajos sobre management -no sólo referentes a las bibliotecas y demás centros de información (como los escritos de Alfons Cornella o los manuales anglosajones ${ }^{1}$ ) sino también los dedicados a la dirección mercantil (manuales de gestión, los últimos best-seller de los mejores gurús de la administración empresarial, los suplementos de economía de los diarios nacionales o los artículos de renombradas revistas de empresariales) - nos han llevado a la convicción de que los mismos principios, teorías, métodos, tácticas, conceptos, etc., que rigen la administración empresarial no son en absoluto ajenos a la gestión de las unidades de información de titularidad pública, aunque con las reservas oportunas en determinados casos.

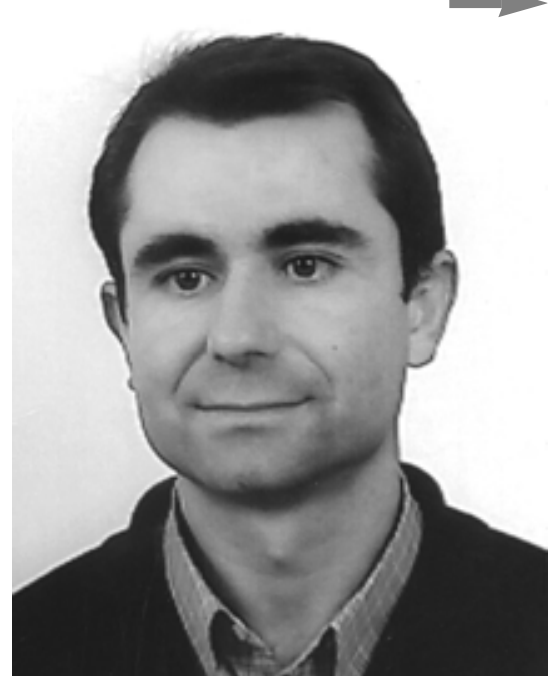

Francisco J. Bonachera 
De este modo, cada vez es más común trabajar en bibliotecas con nociones como liderazgo, calidad ${ }^{2}$, marketing, gestión de recursos humanos, estrategia ${ }^{3}$, coste-eficacia, etc. En el presente análisis nos hemos centrado en un concepto clave en la tarea empresarial: la competencia y, como corolario de la misma, la competitividad (expresión introducida en los años 80 que designa a la capacidad para competir).

El planteamiento propuesto tendrá como hilo conductor el análisis presentado por el economista, investigador y profesor de Harvard, Michael E. Porter, padre del modelo de las fuerzas que determinan la intensidad de la competencia y la ventaja competitiva en la organización industrial ${ }^{4}$.

Explicaremos cuáles son esos componentes y cómo actúan en su entorno y, mediante su aplicación a casos reales, veremos de qué manera operan en la gestión bibliotecaria. Todo esto para llegar a la conclusión de que las reglas que modulan los procesos competitivos en las compañías pueden ser percibidos también en el sector de las bibliotecas. Pero antes que nada, quizá convenga comentar algunas cuestiones acerca de la competencia.

\section{La competencia}

De siempre ha sido el motor de desarrollo y artífice de los grandes cambios que se han producido en las sociedades de cualquier época en la historia de la humanidad, además de ser la fuerza motivadora de todo campo del esfuerzo humano. De este modo, muchos son los que se han quedado en el camino imposibilitados para soportar los costes de la misma siguiendo el más puro paradigma darwiniano de "adaptarse o morir".

Desde el punto de vista de la teoría económica, Ramón Tamames la define en su diccionario ${ }^{5}$ como "la concurrencia de una multitud de vendedores en el mercado libre que, para conseguir la venta de sus productos, pugnan entre sí proponiendo los precios que les permiten sus costes y que se alinean con los del mercado". Arthur Seldon y F. G. Pennance ${ }^{6}$ especi- $^{-}$ fican que la competencia es: "las condiciones de mercado según el grado de control sobre los precios que posean productores y consumidores, dependiendo del número de proveedores y demandantes, de la uniformidad de los bienes y de la libertad de entrada de oferentes potenciales".

\section{«Las reglas que mo- dulan los procesos competitivos en las compañías pueden ser percibidos tam- bién en el sector de las bibliotecas»}

Estas definiciones son del todo clásicas y hacen casi exclusivamente hincapié en los precios. Sin embargo, actualmente, con la eclosión del e-business y del e-commerce, además de la entrada en el juego competitivo de empresas y organismos sin ánimo de lucro que actúan en el mercado ofreciendo unos artículos totalmente nuevos, o que hasta ahora no se les había concedido valor real - los productos de información o derivados de la misma-, las reglas del juego han cambiado y no se habla ya tanto de precios como de posición, impulsión, oportunidad, rapidez, seguridad $\mathrm{y}$, sobre todo, calidad. Estos conceptos tampoco dejan de ser tradicionales pero en la actualidad cobran una dimensión que no habían conocido nunca desde que, cuando se estaban asentando los cimientos de la teoría económica, allá por el siglo XVIII, la competencia adquirió la condición de norma, de patrón de eficiencia al que aspiraban los diferentes siste- mas económicos. Cabría señalar como sus principales ventajas?:

- la asignación eficaz de recursos por medio de los precios que indican los gustos y necesidades de los consumidores,

- la presión sobre los productos para que disminuyan los costes de producción y los precios, con objeto de hacerlos competitivos, y

- la eficiencia dinámica pues supone buscar nuevos productos y oportunidades de mercado.

\section{Competitividad en bibliotecas}

Pero, ¿se puede hablar de competencia cuando se trata del sector público?

Una vez vistos algunos conceptos sobre el tema, veamos cómo los mismos argumentos pueden ser aplicados a la gestión de bibliotecas de titularidad pública según el siguiente análisis: los centros de información de la administración pública están gestionados "a riesgo 0 ". Es decir, su continuidad y existencia no dependen de unos resultados pues es casi imposible que ninguno de estos organismos sea clausurado a no ser bajo circunstancias muy extremas. Además, así debe ser ya que cumplen un servicio público y altruista que de ninguna manera se debería dejar en otras manos, sin que esto presuponga que a los directivos que se ocupan de su gestión no se les exijan determinados frutos.

En este orden de cosas, dado que los recursos son escasos, es imprescindible demostrar un buen rendimiento con objeto de poder obtener nuevamente otros para el ejercicio siguiente. Debería ser evidente que aquel centro que demostrara mayor eficacia en su administración obtuviera mejores asignaciones en capital, material y personal. Como consecuencia de esto no resulta extraño que una biblioteca con un alto grado de utili- 
This is the service that provides the information that is found by the librarian who consults with the VP who formulates the plan to launch the product that beats the competition to market

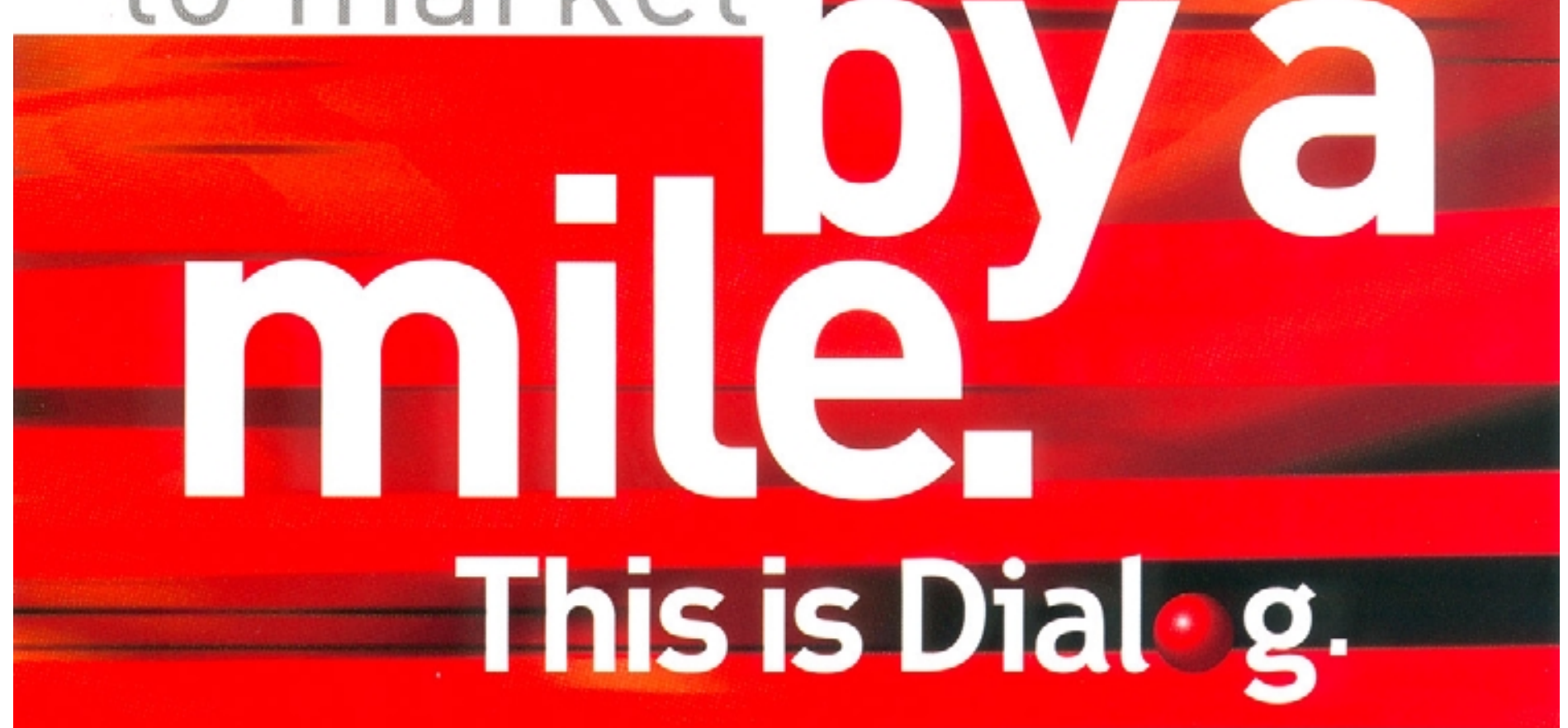

More than 12 terabytes

of content from the world's most authoritative publishers, and the products and tools to search every bit of it with speed and precision. Find out whether a trademark has been registered. Check the financial status of your competition. Research patent information on a new drug. Change the world. With Dialog, it's all in a day's work. To know more, visit www.dialog.com.

For your free information pack, please call +93 4107669 Barcelona, +91 3615434 Madrid or e-mail contact_spain@dialog.com.

\section{THE DIALOG CORPORATION \\ Numancia 85-08029 Barcelona \\ Londres, 17-28028 Madrid}


dad sea foco de atracción para financiación externa de proyectos por el aliciente comercial y publicitario que para las firmas patrocinadoras ello supondría. Ante esta situación su "cuenta de resultados" se vería incrementada.

Por otra parte, la aparición de empresas que prestan determinados servicios que habían sido casi exclusivos de centros informativos - acceso a bases de datos, elaboración de resúmenes, difusión selectiva de la información, por señalar tres ejemplos - ha venido a añadir otra figura más al ambiente competitivo del "negocio" de la documentación. Estas compañías son auténticas competidoras de las unidades de información aunque cobren por sus servicios ya que éstos, aunque no necesariamente, suelen ser más rápidos, ajustados y con mayor valor añadido, por lo que resulta paradójico que el ciudadano tenga que pagar el "doble" por unos productos informativos. Por un lado a la empresa privada que se lo presta directamente; por otro financiando mediante el pago de sus impuestos a la institución que debería prestárselos.

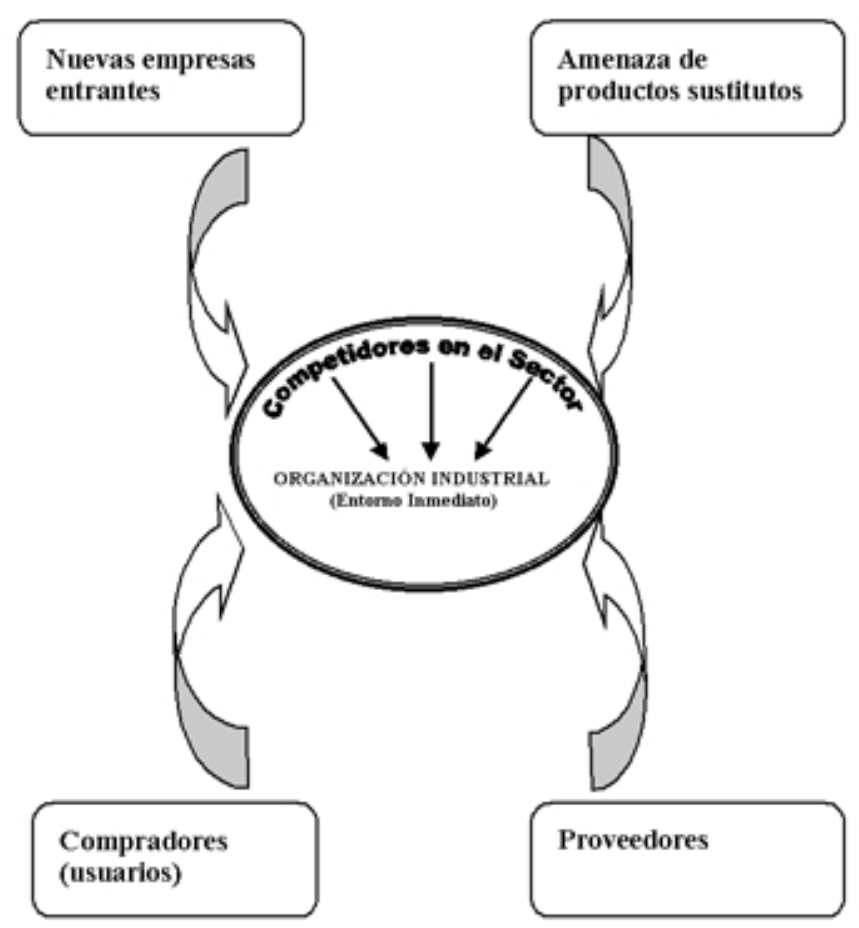

Figura 1
Resolver esta paradoja y competir, en el sentido literal de la palabra, con el sector privado es labor primordial y de derecho por parte de nuestros archivos, bibliotecas y centros de documentación.

\section{Ambiente competitivo}

Hablar de competitividad implica irremediablemente, tal y como se ha comentado con anterioridad, citar a Michael E. Porter y cómo sus teorías sobre la competencia pueden ser, al menos en gran medida, aplicadas a la gestión de unidades de información gestionadas "sin riesgo". Las cinco fuerzas competitivas propuestas por este autor son:

— La rivalidad entre las firmas existentes.

— La amenaza de la entrada de nuevas empresas.

-El desafío que supone la aparición de productos sustitutos.

-El poder de negociación de los compradores.

- La capacidad de negociación de los proveedores.

Puede observarse todo ello de manera esquematizada en la figura 1.

\section{Rivalidad entre las firmas existentes}

Antes de analizar cómo influyen las empresas pertenecientes a una misma área en el movimiento competitivo debemos comentar dos conceptos. Por lo común cualquier estructura comercial o industrial oscila entre dos polos opuestos: el monopolio y la competencia perfecta, ocurriendo el primero cuando existe un único oferente en exclusiva de productos/servicios en su mercado. Por su parte, la competencia perfecta supone la concurrencia en el sector de un número suficientemente elevado de oferentes y demandantes del producto/servicio de manera que se produce un equilibrio "perfecto" entre oferta y demanda resolviéndose éste mediante los precios, la rapidez y la calidad.

Estas situaciones no se producen en prácticamente ningún sector de la actividad económica, ya que son precisamente los "fallos" en el mercado los que hacen que una empresa consiga beneficios por encima de las demás. En este ambiente, la rivalidad entre los competidores es la forma más común de competencia y se produce cuando una o más de las firmas siente la necesidad de mejorar su posición.

Tras la fase emergente de los primeros tiempos existe un momento en que una biblioteca percibe que la prestación de sus servicios, el número de usuarios, la satisfacción de los mismos, la búsqueda de financiación alternativa, etc., están estancados. Se ha pasado a una etapa de madurez y ha llegado el momento de moverse ideando nuevos servicios, productos imaginativos, difusión más ajustada, fuentes de capital novedosas, maneras de optimizar los escasos recursos, etc., que le hagan aprovecharse de las oportunidades del ambiente. Es un período crítico en el que cobra gran importancia la investigación para innovación de los procesos y los servicios. Sin embargo no debe caerse en el exceso de interés en productos creativos $y$ novedosos desatendiendo la mejora enérgica de los ya existentes.

Cualquier movimiento de este tipo provoca una reacción inmediata en el sector de manera que las 
demás firmas procurarán poner su potencial al servicio de la competencia "contra" la primera organización. Además, la lucha competitiva suele afectar a todo el contexto y a los organismos que lo componen por lo que es muy común que todos salgan beneficiados. Sirva como ejemplo el gran auge que han tenido los fondos a alto interés de las divisiones electrónicas de los mejores bancos mundiales: ING Direct, EvolveBank, Uno-e, etc., con suscripciones masivas de rentistas.

Por ello no resultará raro que si una biblioteca realiza unos movimientos de este tipo, las situadas en su entorno, aunque sea por mero amor propio, se apuntarán a ese juego de competitividad con lo que los usuarios serán los grandes beneficiarios.

Un buen ejemplo de esto lo encontramos si volvemos atrás en el tiempo, en el verano de 1999, cuando la Biblioteca de Andalucía sacó a la luz un servicio de referencia electrónica a través de su página web llamado "La biblioteca responde" . Para principios del año siguiente, el Ministerio de Cultura puso en marcha un proyecto similar denominado "Pregunte: las bibliotecas responden" al que están suscritas numerosas bibliotecas públicas y regionales de España y que resuelven cientos de requerimientos informativos cada mes.

\section{Amenaza de entrada de nuevas firmas}

Dentro del segmento de la sociedad actual a la que llamamos de la información, las bibliotecas ocupan un lugar cada vez más preponderante pero, por la rapidez y complejidad de los cambios operados en la misma, les es cada vez más difícil percibir su lugar en ella. Ante esta situación, son muchas las empresas privadas que buscan su oportunidad, aprovechando esta falta de posicionamiento de los or- ganismos que tradicionalmente han explotado los recursos informativos: bibliotecas, centros de documentación y archivos, por el atractivo de un sector que ofrece grandes posibilidades de negocio.

Estas compañías, muchas de las cuales conocen la especial estructura del campo de acción puesto que han trabajado para bibliotecas cuando éstas han externalizado algún servicio, cuentan con la ventaja de la tecnología, suelen ser más arriesgadas, creativas y, aunque evidentemente cobran por sus servicios, su gran valor añadido las hacen atractivas a los usuarios si los costes son competitivos.

\section{«La aparición de em- presas que prestan determinados servi- cios que habían sido casi exclusivos de centros informativos ha venido a añadir otra figura más al ambiente competitivo del 'negocio' de la documentación»}

También nos encontramos con librerías en algunas grandes ciudades a las que se puede acudir a leer sin necesidad de comprar nada, con otros servicios alternativos como cafetería y restaurante, promoción de actividades culturales, presentaciones de libros, etc. (claro que siempre con la idea de que este atractivo ambiente anime el consumo de sus productos). Aunque un poco de lejos, dado que no están demasiado extendidas, podrían ser un sustituto del hecho de acudir a las bibliotecas.

Éstas pueden y deben poner barreras a esas entradas en su campo de actividad. Una de ellas podría venir de parte de la administración, inyectando capital y cualquier otro tipo de recursos a las unidades informativas de manera que mejoren sus servicios para que sus "clientes" no se vean obligados a acudir a organizaciones con ánimo de lucro con el fin satisfacer sus necesidades de conocimiento.

Por otro lado, los centros informativos disponen ya de una imagen de marca y de una reputación ante los ciudadanos que tendrán que consolidar o mejorar según los casos a fin de conseguir su fidelidad ya que cuando un cliente demuestra su confianza en una marca supone todo lo excelente que está detrás de ella. El problema se presenta porque es muy difícil valorar el grado de impacto ante el usuario de este activo intangible, siendo complicada su valoración y contabilización.

Esto lo pudimos comprobar durante nuestra experiencia como responsables técnicos de la sección de cartografía de la Biblioteca de Andalucía. Observamos que muchos alumnos de las facultades de ciencias cercanas hacían un uso habitual de nuestra colección de mapas, cuando ellas poseen su propio repertorio. La razón nos la dieron ellos mismos: la nuestra es bastante completa y variada, está muy bien organizada y damos muchas facilidades para su acceso. Por tanto, los alumnos que vienen a consultar nuestra cartografía perciben que detrás de este fondo está la "marca" de la Biblioteca de Andalucía.

En otro orden de cosas, estas unidades sin ánimo de lucro cuentan con la gran ventaja de la gratuidad de sus productos, que les debería hacer por fuerza los más competitivos si a ello le añaden la calidad, la rapidez y el ajuste.

Un ejemplo claro de esta clase de competencia la tenemos en el convenio que la Sociedad Genealógica de Utah (organización no lucrativa financiada por la Iglesia de Jesucristo de los Santos de los Últimos Días, los mormones) firmó con el Ministerio de Cultura hace 
unos años de manera que este organismo microfilmaba los documentos de archivos españoles (históri$\cos$, municipales, diocesanos, conventuales, notariales, etc.) a cambio de dejar una copia en los respectivos archivos, otra en el Centro $\mathrm{Na}$ cional de Microfilm y otra la guardaban ellos en su archivo en Utah. A estos materiales, que son distribuidos a todos los centros con que cuentan en el mundo, pueden acceder libremente los fieles de esa confesión para resolver sus necesidades informativas e incluso personas no adeptas a sus creencias. No es raro, además, verlos establecidos en algunos aeropuertos internacionales. Todos estos servicios son prestados de manera gratuita.

\section{Amenaza de productos sustitutos}

Normalmente suelen aparecer en escena de manera rápida cuando aumenta la competencia en el sector debido a los nuevos adelantos, a la reducción de los precios y a la mejora de sus rendimientos.

Dentro del contexto en el cual nos movemos podrían considerarse los productos informativos y de fuentes de información tanto directas como indirectas en soporte electrónico (enciclopedias, diccionarios, manuales, revistas, productos divulgativos, cursos y materiales didácticos de diversas clases, bibliografías de cualquier tipo, etc., todo ello en cd-rom) en los cuales las editoriales más fuertes están haciendo grandes esfuerzos financieros observando la enorme aceptación que están teniendo estas utilidades con las que el usuario puede acceder, a un precio bastante asequible, a una serie de capacidades muy atractivas y cada vez de mayor calidad sin necesidad de acercarse a su biblioteca. De esta forma no tiene que perder el tiempo en desplazamientos, esperas y búsqueda de una ubicación adecuada dentro del recinto bibliotecario.
Y cómo no internet, que puede ser considerado el producto estrella, que hace posible el acceso desde casa al "libro más grande del mundo". No vamos ahora a descubrir su potencial informativo, pero la posibilidad de encontrar libros electrónicos, de buscar en catálogos de casi todas las bibliotecas y de conseguir información de prácticamente cualquier materia, la hacen muy atractiva como producto sustituto de las bibliotecas tradicionales.

Como consecuencia nuestros centros deberán reaccionar haciendo que su sala de referencia salga también fuera de sus barreras arquitectónicas fortaleciendo o creando una página web en la que ofrecer y mejorar los mismos servicios pero de manera digital traspasando el mero hecho de la página como un "folleto" electrónico de la biblioteca ${ }^{10}$.

Por ejemplo, la Biblioteca Nacional permite solicitar reproducción de documentos de manera electrónica ${ }^{11}$; la Biblioteca de Castilla y León ofrece acceso gratuito a la revista digital El correo bibliotecario $^{12}$; el programa de gestión Absys utilizado, entre otras, por las Bibliotecas Públicas Provinciales de Andalucía presenta la utilidad de poder reservar libros en préstamo vía web, etc.

Con todo, no se puede descuidar la atención del usuario en sus locales, ni desmontar un servicio de referencia in situ por dedicar todas las energías al servicio remoto, por lo demás, incierto en muchos aspectos.

\section{Poder de los usuarios}

En las bibliotecas de titularidad pública, cuya función es eminentemente social, la atención al "comprador" de sus servicios, los usuarios, se manifiesta como un poderoso acicate y la principal fuerza motivadora de la competitividad en su gestión.

Ante las compañías con ánimo de lucro la principal arma que esgrimen los clientes a la hora de adquirir los productos suelen ser los precios. En nuestros centros informativos, por su propio espíritu de servicio público, es evidente que el usuario no buscará su rebaja puesto que las tarifas son inexistentes. Sin embargo, a cambio exigirá unos servicios diferenciados, rápidos y de calidad bajo la "amenaza" de acudir a productos sustitutos o a las nuevas empresas de servicios que han entrado en el sector de la información.

El "consumidor" actual de las bibliotecas está más informado, con lo que presionará más en busca de mejores servicios. De ahí la crucial importancia de fidelizarlo y de prestar mejor atención a los usuarios existentes, más que pensar a toda costa en la búsqueda de nuevos (las empresas tienen claro que resulta más caro hacer un cliente nuevo que mantener a uno actual). Hacia él deben ir dirigidas las campañas de marketing de las bibliotecas, y por él el centro debe cuidar su imagen y reputación.

Un aspecto cada vez más tenido en cuenta por las compañías consiste en fortalecer la fidelización de sus "clientes internos", esto es, los trabajadores del centro. Son una gran fuerza que espolea la competitividad de los organismos, con el fin de evitar dos situaciones de gran actualidad: la "fuga de cerebros" y el efecto burn-out (o "síndrome de estar quemado") ${ }^{13}$.

En el primero de los casos, algunas compañías llegan hasta extremos insospechados. Aparte de ofrecer todo tipo de comodidades ergonómicas en las oficinas, también incluyen servicios gratuitos de restaurante, cafetería, masajes, gimnasio, etc., además de propiciar tiempo libre por cierto número de 


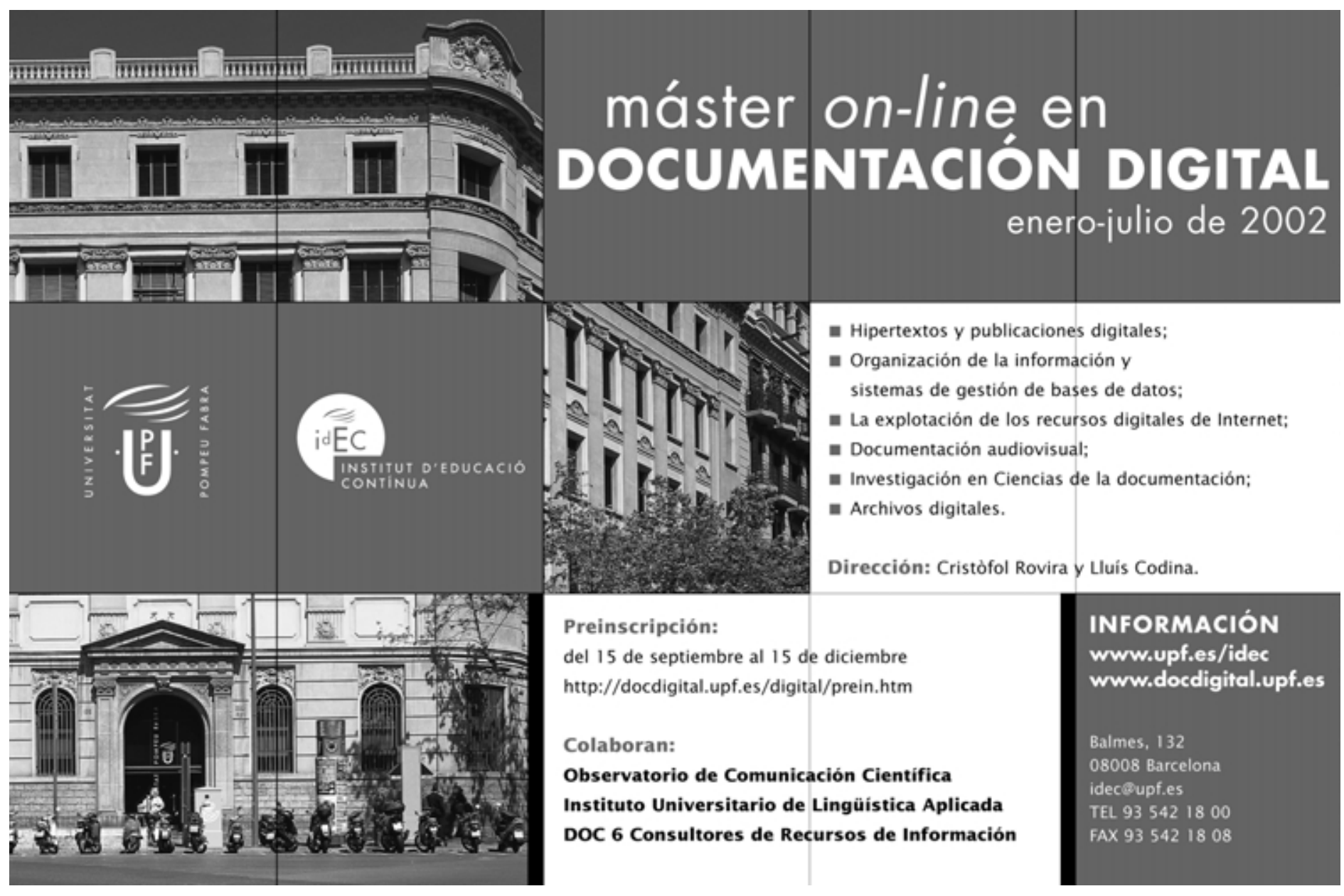

horas trabajadas al año con el fin de que el empleado las pueda dedicar a colaborar, por ej., con $O N G$ s ya que mucha gente está interesada en participar en actividades de este u otro tipo pero el trabajo se lo impide.

Respecto al burn-out, los directivos procuran delegar cada vez más responsabilidades a los trabajadores, motivándoles a que tomen sus propias decisiones. También les hacen partícipes del análisis y valoración de su puesto de trabajo, de manera que se llegue a un equilibrio satisfactorio entre las necesidades de la empresa y sus inquietudes y aptitudes, con el consiguiente incremento del rendimiento. Por otra parte cada vez se está fomentando más el surgimiento de las llamadas "comunidades de prácticas", grupos informales de trabajadores de un mismo centro que aprenden unos de las experiencias de otros de manera no canalizada y que hacen que el propio organismo aumente su aprendizaje ${ }^{14}$.

\section{El poder de regateo o de negociación de los proveedores}

Por lo general los suministradores pueden ejercer su poder de negociación sobre las empresas mediante el aumento de los precios o la reducción de la calidad de los productos o servicios que se les solicitan. Por la responsabilidad que tienen los organismos públicos de responder de la adecuada inversión del capital que se les ha asignado, proveniente de las cargas impositivas a los ciudadanos, éstos deberán buscar los mejores proveedores en la medida de sus posibilidades.

Es una exigencia que las bibliotecas seleccionen cuidadosamente tanto a los suministradores de productos (quienes les sirven material de oficina, libros, suscripciones a revistas, productos informáticos, etc.) como a las empresas de servicios a las que contraten en caso de externalizar algún trabajo (catalogaciones retrospectivas, vaciado de publicaciones periódicas, microfilmación o digitalización de documentos, etc.) buscando la mejor proporción coste-eficacia, alta calidad, servicio rápido y transparencia en las gestiones. Pero todo ello sin perder de vista que se deben ajustar a las especiales formas de pago que tiene la Administración, condiciones a las que desgraciadamente no todos los proveedores pueden hacer frente, en especial los pequeños.

Esta selección se convertirá en crítica en el momento en que los recursos económicos del centro sean escasos, las posibilidades de elección estén limitadas por cualquier circunstancia, cuando los costes de cambio (esto es, los gastos fijos que el comprador debe asumir al cambiar de proveedor) sean altos o no haya productos sustitutivos adecuados. 
En el Archivo de la Chancillería de Granada, dado que es un centro con recursos económicos nunca suficientes y no posee un control directo sobre su presupuesto (como el resto de las unidades dependientes de las delegaciones provinciales de la Consejería de Cultura de la Junta de Andalucía), la compra de libros para la biblioteca auxiliar se dejó de realizar a través de las firmas comerciales que nos proporcionaban sus catálogos ya que los gastos de intermediación eran muy altos. Además, el tiempo medio de recepción del ejemplar era excesivo para nuestras necesidades pues, al ser una biblioteca muy especializada, necesitábamos acortar el momento de llegada. A todo esto hay que añadir que estas empresas no asumían con facilidad el cobro a meses vista de sus facturas. La solución la encontramos en la negociación con una librería de la ciudad que rebajaba los costes por ejercer de intermediaria, asumía nuestra forma de pago aplazado y se comprometía a acelerar los trámites para la rápida obtención del libro.

\section{Últimas consideraciones}

Como complemento a sus análisis de las 5 fuerzas, Porter nos ofrece una serie de estrategias genéricas que redondearían sus tesis competitivas y que pueden ser tenidas en cuenta a la hora de gestionar las bibliotecas, a saber ${ }^{15}$.

-Liderazgo de costo: se trataría de reducir los costes de manera que se mejore la competitividad de precios o la rentabilidad de los productos; aplicado sobre todo en unidades que gestionan poco presupuesto y deben servir a una amplia población, valga el caso de las bibliotecas municipales.

—Diferenciación: con objeto de ofertar productos únicos y singulares, por ejemplo las historias clínicas del Centro de Documenta- ción del Hospital Clínico de Granada.

-Enfoque: centrarse en un grupo específico de usuarios, en una línea de productos o en una demarcación geográfica; esto sería aplicable a las bibliotecas especializadas o especiales como la $\mathrm{Bi}$ blioteca de Andalucía o el Centro de Documentación Musical de Andalucía.

Al planteamiento propuesto por este autor se le ha achacado desde diferentes ámbitos su excesiva atención al entorno externo sin casi apenas tener en cuenta el ambiente inmediato, interno, de las compañías. Porter lo hace con toda la intención ya que parte de la base de que los organismos ya tienen identificadas tanto sus debilidades como sus fortalezas y que ya están realizando su análisis dafo (debilidades, amenazas, fortalezas y oportunidades, swot en inglés) con el fin de hacer frente a sus amenazas y aprovechar sus oportunidades. Además de todo esto, él mismo publicó más adelante una serie de matrices donde daba cuenta de los factores internos que intervenían en la competitividad de las empresas.

\section{Conclusiones}

A lo largo de este texto, tras la declaración de objetivos y algunas apreciaciones sobre la competencia, hemos pretendido significar de qué manera afectan los impulsos que agitan los mecanismos competitivos en el entorno mercantil a la gestión de bibliotecas de la administración y, a través de ejemplos reales basados en la experiencia, hemos pretendido ilustrar los argumentos expuestos.

En nuestra opinión las pautas que presiden la gestión empresarial son válidas también para la dirección y administración de los centros informativos sin ánimo de lucro y que éstos necesitan posicio- narse en su sector de manera que cumplan con eficiencia la misión no lucrativa que tienen encomendada.

Por todo esto resulta crítico que toda persona con capacidad de decisión en la gestión de bibliotecas ponga su empeño en tratar de identificar las amenazas dentro y fuera de su ámbito de actuación y obrar en consecuencia, estableciendo las barreras necesarias o aprovechando las ventajas competitivas propias de su organización. Además, consideramos clave la necesidad de rentabilizar a tal efecto el capital humano e intelectual de estos organismos, quizá uno de los activos menos conocidos y explotados por la administración pública.

\section{Notas}

1. De los mejores: Stueart, Robert D.;

Moran, B. B. Gestión de bibliotecas y centros de información. Barcelona: Diputació, 1998. Weingand, D. E. Managing today's library: blueprint for change. Englewood, Colo.: Libraries Unlimited, 1994. Está siendo traducido por capítulos en el Boletín de la Asociación andaluza de bibliotecarios en los números: 46 (1997), 49 (1997), 51 (1998), 54 (1999), 55 (1999), 56 (1999), 57 (1999), 58 (2000), 59 (2000), 61 (2000).

2. Véase el plan de evaluación y mejora de la biblioteca de la Universitat de Barcelona. http://www.bib.ub.es/bub/avalua/avalua.htm

3. Casi todo lo que hay que conocer sobre la estrategia lo encontramos en: Mintzberg, H.; Quinn, J. B.; Ghoshal, S. (eds.). El proceso estratégico. Madrid: Prentice Hall Ibérica, 1998.

4. Publicadas por primera vez en: Porter, M. E. Competitive strategy: techniques for analysing industries and competitors. New York: Free Press, 1980.

5. Tamames, R. Diccionario de economía. $6^{\mathrm{a}}$ ed. rev. y amp. Madrid: Alianza Ed., 1993.

6. Seldon, A.; Pennance, F. G. Diccionario de economía. Barcelona: Oikos, 1986.

7. Citadas en: Deane, P.; Kuper, J. (eds.). Vocabulario básico de economía. Barcelona: Ed. Crítica, 1992.

8. Se puede consultar en:

http://www.sba.junta-andalucia.es

9. Accesible en:

http://pregunte.carm.es 


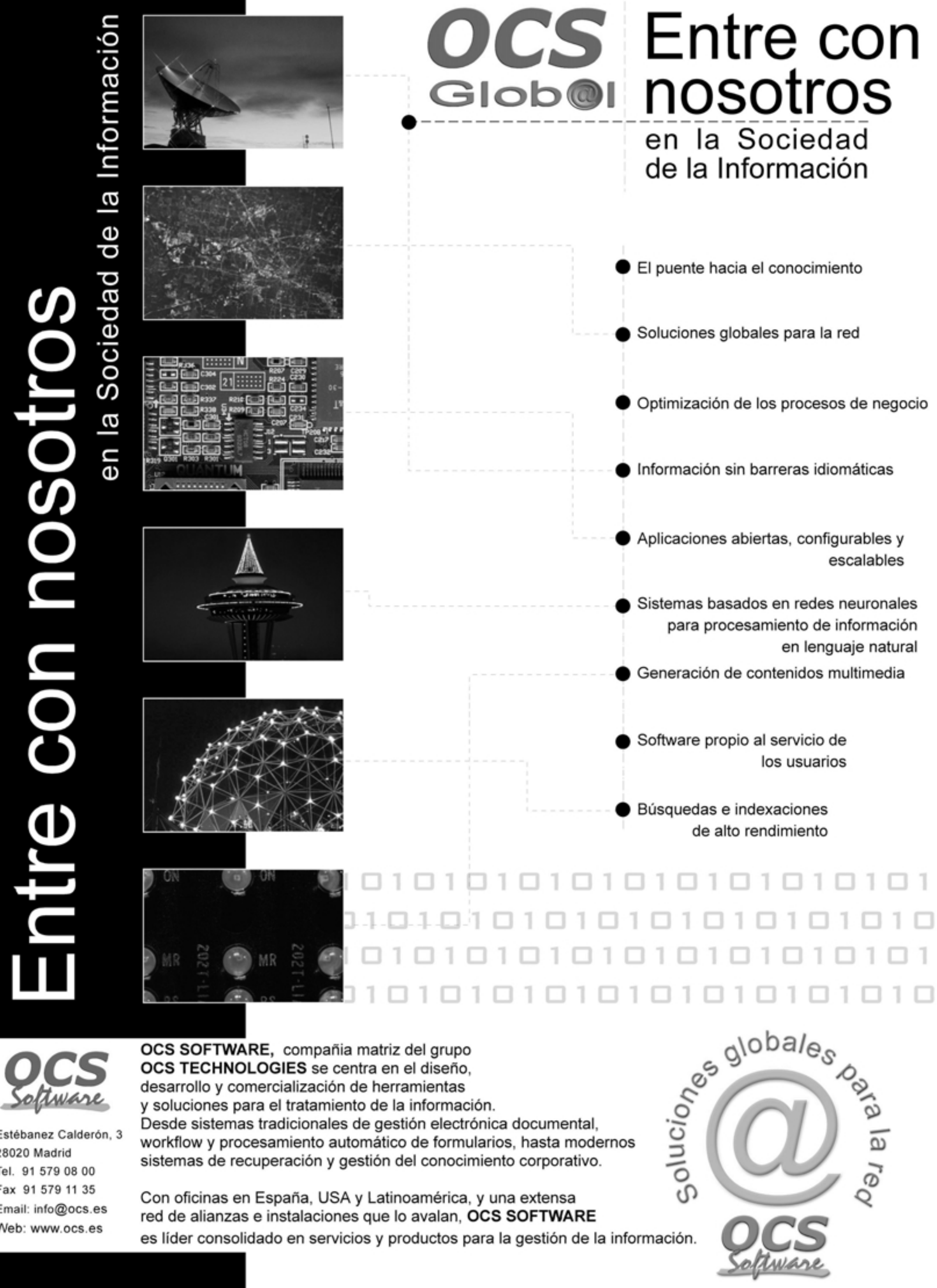


10. Sobre esto se puede leer: Estivill, A.; Abadal, E. "Acceso a los recursos web gratuitos desde las bibliotecas". En: El profesional de la información, 2000, noviembre, v. 9, n. 11, pp. 4-16.

11. http://www.bne.es/esp/colec-fra.htm

12. http://www.bcl.jcyl.es/correo/index.html

13. Véase: "El síndrome de estar quemado". En: Ceac empresa: revista de la actualidad empresarial, 2001, febrero, n. 147, pp. 39-40.
14. Véase: Sánchez, L. "Los verdaderos dueños del conocimiento". En: $A B C$ nuevo trabajo, 3 de diciembre de 2000.

15. Citadas por: Gray, E. R.; Smeltzer, L. R. Management: the competitive edge. Maxwell MacMillan International Ed., 1990, pp. 234240. Una traducción de las mismas realizada por R. J. Aguado se puede consultar en:

http://spin.com.mx/ rjaguado/amb.html
Deudas de gratitud: por su orientación y "refinado" del presente trabajo, queremos dar las gracias a Juan Carlos Fernández Molina (de la Facultad de Biblioteconomía y Documentación de la Universidad de Granada) y a Alicia del Pozo López (del CRC de Axesor, Grupo Infotel).

Francisco J. Bonachera Cano. Servicio de Documentación y Biblioteca, Archivo de la Real Chancillería, Granada. 